\title{
Movimientos peligrosos Aby Warburg, entre el cine y el viaje
}

\author{
Dangerous Movements \\ Aby Warburg, between Journey and Cinema
}

\author{
Federico Luis Ruvituso \\ federicoruvituso@gmail.com \\ Instituto de Historia del Arte \\ Argentino y Americano \\ Facultad de Bellas Artes \\ Universidad Nacional de La Plata \\ Argentina
}

Reseña a Philippe-Alain Michaud (2017). Aby Warburg y la imagen en movimiento. Buenos Aires, Argentina: Libros UNA, 286 páginas

Recibido: $18 / 9 / 2017$ Aceptado: 5/1/2018

\begin{abstract}
Resumen
En esta reseña se sugiere una lectura en clave historiográfica del libro Aby Warburg y la imagen en movimiento (2017), de Philippe-Alain Michaud. La edición castellana de este profético trabajo ofrece una interpretación polémica de la obra warburguiana. Tomando como punto de partida una original filiación entre los inicios de la iconología y las primeras experiencias cinematográficas, Michaud señala cómo las investigaciones warburguianas desembocaron en una teoría sobre el movimiento como forma de investigación. Esta reseña sigue los pasos de tal hipótesis y ofrece una adenda crítica acerca de la función que tuvo, en la obra de Warburg, ese peculiar viaje que intentó poner en movimiento a la historia del arte decimonónica.
\end{abstract}

\section{Palabras clave}

Warburg; iconología; movimiento; estudios cinematográficos

\section{Abstract}

This review suggests a historiographic interpretation of the book Aby Warburg and the Image in Motion (2017) by Philippe-Alain Michaud. The Spanish edition of this prophetic work offers a controversial interpretation of the Warburguian work. Starting from an original connection between the beginnings of the iconology and the first cinematographic experiences, Michaud points out how the Warburguian investigations fall into a theory about movement as a form of investigation. This review follows the steps of this hypothesis and offers a critical addendum about the role played in Warburg's work for this peculiar journey that tries to set in motion the Art History of the nineteenth century.

\section{Keywords}

Warburg; iconology; motion; cinematographic studies 
1 Nos referimos aquí al artículo «De Aby Warburg a Ernst Gombrich» publicado en 1986 en Miti, Emblemi e Spie, donde Carlo Guinzburg se adentra en las obras de Fritz Saxl, Erwin Panofsky, Edgar Wind y el propio Gombrich, entre otros, para señalar el cambio de paradigma que sufrió el legado de Warburg en manos de sus continuadores directos (Guinzburg, 2013, pp. 51-125).

2 La literatura sobre Warburg es ya más vasta que su obra y sería imposible resumir aquí su impacto en Latinoamérica. En la Argentina, al mencionado trabajo especializado de Burucúa (2003) le anteceden, por lo menos, dos textos fundamentales para la difusión académica del personaje: Historia de las imágenes e historia de las ideas. La escuela de Aby Warburg (1992) y las publicaciones de corte warburguiano en Cuadernos del Sur a cargo de Héctor Ciocchini, scholar argentino que estudió en el instituto Warburg durante los años sesenta y setenta y que propagó la perspectiva del instituto entre diversos intelectuales argentinos. La mayoría de los trabajos de Didi-Huberman y de Gombrich sobre el autor tuvieron ediciones españolas ampliamente difundidas.
La edición castellana de Aby Warburg et l'image en mouvement (1995) abre la colección de Libros UNA con un texto casi profético. El trabajo de Philippe-Alain Michaud -reconocido teórico del cine- apareció por primera vez hace casi treinta años en un contexto muy diferente al actual, cuando el interés por la obra del gran historiador del arte hamburgués todavía no había salido de reservados círculos intelectuales. En esos años, los trabajos de Aby Warburg no se leían aún bajo la interpretación nietzscheana de Georges Didi-Huberman (2002) y la discutida biografía que le dedicó Ernst Gombrich al personaje en 1986 mantenía todavía su autoridad intacta, a pesar de que ese mismo año Carlo Guinzburg (2013) lanzara una diatriba magistral a propósito de la iconología postwarburguiana. ${ }^{1}$ En la Argentina, el ostracismo warburguiano se atenuaba recién en 2003 con la publicación de Historia, arte, cultura. De Aby Warburg a Carlo Ginzburg, de José Emilio Burucúa, para complicarse, tiempo después, con la aparición de algunas traducciones de los ensayos de Didi-Huberman sobre el autor. En Francia, el libro de Michaud fue el primer libro íntegramente dedicado al historiador del arte alemán; el primero de un sinfín de trabajos dedicados al autor que le sucedieron.

Estas exégesis dispares construyeron, junto con otras, ${ }^{2}$ una figura difícil de seguir, un fantasma tutelar cuya interpretación osciló entre lecturas muy historiográficas y sobreinterpretaciones demasiado entusiastas a partir de un legado intelectual irremediablemente fragmentado, quizás, de forma intencional por el propio Warburg. Pese a ello, la apasionada supervivencia sobre una obra como la de Warburg, en tiempos que se dicen interdisciplinarios como los nuestros sugiere, sin entrar en detalles, una nueva (vieja) impronta para las siempre vapuleadas disciplinas auxiliares, como son, por ejemplo, la historia del arte y la iconología.

En este contexto, la temprana propuesta de Michaud -que acerca la iconología a los análisis cinematográficos- reclama especial atención para retomar la pregunta sobre la actualidad warburguiana, sus evidentes potencias y sus problemáticas limitaciones.

En una lectura a contrapelo del trabajo de Michaud, el acercamiento argumentativo que el francés propone entre los experimentos cinematográficos de fines del mil ochocientos y la teoría warburguiana parece tener que ver más con una sensibilidad de época que con una relación a priori. Es sabido que las menciones del cine en la obra de Warburg son muy marginales, a pesar de su evidente obsesión por el estudio de las imágenes que expresan algún tipo de movimiento. Sin embargo, insiste Michaud, el progresivo pasaje entre el estudio de figuras en movimiento en la obra de Warburg hasta llegar al sistema de montaje con imágenes en el Atlas Mnemosyne "[...] está totalmente sustentado por la estética del movimiento que se expresa, desde fines del siglo XIX, en el cine naciente» (2017, p. 35).

En este sentido, el primer cine entendido como una manera de pensar la imagen en movimiento más allá de su carácter espectacular 
3 El trabajo de Michaud considera la noción de film como una forma de encadenar conceptualmente imágenes sin la necesidad del dispositivo cinematográfico en celuloide, que sería solo una mejora técnica fundamental. El film, en estos términos, podría acercar la labor del cineasta a la del historiador del arte a partir de una vieja presunción que Sergei Eisenstein expondría al proponer el juego perceptivo de la arquitectura antigua o la catedral gótica como formas de film (Eisenstein, 1989). o, mejor, en términos de Warburg, como un espacio de pensamiento (Denkraum), se acercaría a la historia del arte warburguiana, una historia centrada en comprender la repetición o la supervivencia en el universo de las representaciones. En ese sentido, Michaud propone interpretar todos los esfuerzos de Warburg bajo la imagen de un interés por el movimiento, compartido con la incipiente técnica cinemática de su tiempo.

De esta manera, la concepción - tan cinematográfica- del montaje que se expresa de forma evidente en el Atlas Mnemosyne (considerado, según Michaud, como una forma de film), ${ }^{3}$ representa en la obra de Warburg la síntesis de una elaborada teoría que intenta descifrar los motivos que animan y que reaniman las imágenes del pasado en el presente. Una idea que se expresó muy temprano en los trabajos académicos de Warburg, sustancialmente, en el estudio de las supervivencias de la Antigüedad en el estilo ideal del Renacimiento y que, tiempo después, intentaría alcanzar horizontes temporales más amplios a través de las Pathosformeln. Como afirma Didi-Huberman, en consonancia con Michaud al referirse al problema del desplazamiento y de lafalta de centro en la obra warburguiana, Warburg pensaba el movimiento "[...] como objeto y como método, como sintagma y como paradigma, como característica de las obras de arte y como postura misma del saber que pretende decir algo de esto" (Didi-Huberman, 2017, p. 19).

La iconología del intervalo (Die Ikonologie des Zwischenraumes), una de las muchas maneras que tenía Warburg de referirse a su práctica con las imágenes, sería en esta lectura un desplazamiento, un viaje para poner la historia del arte en movimiento. La propuesta del francés, además de una sugerente metáfora sobre la obra warburguiana, se define, en gran medida, a partir de una consideración especial con respecto a los avatares de la vida espiritual del historiador.

El viaje fue para Warburg no solo una cuestión intelectual que le permitía interpretar a los hombres de la Florencia del mil quinientos, sino que significó literalmente para él una experiencia vital aparentemente determinante. Por esta razón, a la luz del cruce con el cine y con la idea de movimiento, Michaud se propone acercar los artículos de Warburg y los mecanismos de montaje de su Atlas Mnemosyne, en consonancia con el primer cine de fines del XIX, a las experiencias con los indios hopi que un Warburg de veintinueve años presenciaba alucinado en el célebre viaje a la Nueva México de 1895. El viaje americano fue el espacio donde Warburg encontró la clave para su teoría sobre el movimiento, justamente, lejos de los libros y de los archivos florentinos, en una aventura en territorio desconocido.

La propuesta de Michaud es tan arriesgada como original. En último término, propone adentrarse en el problema (y en los peligros) de la quizás decisiva influencia que pueden ejercer los efectos y las impresiones de una experiencia con fenómenos culturales vivos al momento de interpretar una cultura del pasado irremediablemente inaccesible. 
4 Nos referimos aquí a El nacimiento de Venusy la Primavera de Sandro Botticelli. Una investigación sobre las representaciones de la Antigüedad en el Primer Renacimiento italiano, publicado en 1893.

5 El trabajo sobre las fiestas florentinas se titula El vestuario de los intermezzi de 1589. Los diseños de Bernardo Buontalenti y El Libro de Cuentas de Emilio de 'Cavalieri, publicado en 1895.

6 «Lo que me interesaba como historiador cultural era que, en medio de un país que había hecho de la cultura técnica una admirable arma de precisión al servicio intelectual, pudiera conservarse el enclave de una clase humana, primitiva y pagana» (Warburg, 2008, p. 12).
A estos efectos, los capítulos de Aby Warburg y la imagen en movimiento (2017) se consolidan como si se tratase de la explicación de un hipotético panel final ausente en el incompleto Atlas Mnemosyne, que pretende aproximarse al espíritu general de todo el proyecto, a su primigenia y a su oscura analogía entre la sensibilidad del Renacimiento y los rituales hopi, y a los principios procedimentales compartidos con las primeras experiencias cinematográficas de fin de siglo.

En ese sentido, resonarán en el texto de Michaud interesantes analogías de las obras de Warburg y los daguerrotipos de 1839, los registros de William Kennedy Laurie Dickson a partir de las danzas sioux, en 1934, o los estudios estereoscópicos que Etienne-Jules Marey realizaba para captar ondas de movimiento, realizados durante los mismos años en los que el joven Warburg defendía su tesis sobre el influjo de la antigüedad en Botticelli. ${ }^{4} \mathrm{~A}$ su vez, estos ecos se alternan con el análisis de algunos artículos warburguianos que el autor pone a dialogar directamente con la experiencia de los hopi (a pesar de no aparecer referenciada en ninguno de ellos). Así, los intermezzos florentinos, aquellas artificiosas fiestas donde las figuras paganas volvían literalmente a la vida a través de la danza, la música, el teatro y los gestos imaginativamente clásicos (que Warburg reconstruyó parcialmente a partir del inagotable archivo florentino), revelaban su frenetismo a la luz de su experiencia con los indios. Algunos meses después de la publicación de este trabajo, ${ }^{5}$ Warburg emprendió el viaje y experimentó in vivo los fenómenos de supervivencia antigua que había observado en los intermezzos. Las danzas tradicionales hopi le permitieron, así, reconstruir el sentido de estas fiestas en una clave dionisíaca gracias a un entrecruzamiento, según Michaud, «[...] de proximidad (Annäherung) y de extrañeza (Unheimlichkeit)» (2017, p. 141).

La insistencia de Warburg en el carácter dionisíaco de la cultura del Renacimiento, intuición nietzscheana en algunos aspectos, se basaba, en parte, en el abandono del estatismo sereno con el que Joachim Johannes Winckelmann había caracterizado el arte antiguo $-\mathrm{y}$, por continuación, el del Renacimiento- $\mathrm{y}$ en el rechazo warburguiano a la historia del arte esteticista, que había popularizado el mármol neoclásico. La búsqueda de Warburg en favor de la caracterización del arte del Renacimiento como una cultura conflictiva y ambivalente que habría tomado de la antigüedad un primitivo sentido del movimiento y la acción, no podía advertirse bajo el disfraz de la «[...] unilateral consideración estética» habitual entre los historiadores del arte de su tiempo (Warburg, 2014, p. 196). Por esta razón, el contacto con lo que Warburg creía que era una de las últimas culturas primitivas supervivientes, los nativos americanos, tenía especial relevancia para su estudio del Renacimiento, a pesar de su relación aparentemente muy remota. A partir de este acercamiento semiantropológico a culturas que sobrevivían con esfuerzo al proceso de modernización norteamericano, Warburg esperaba encontrar la clave y los modos de la supervivencia (Nachleben) del paganismo en el Quattrocento. ${ }^{6}$ 
7 Nos referimos aquí a "Arte flamenco y primer Renacimiento florentino» editado por primera vez en 1902 (Warburg, 2005, pp. 229-247).
8 Wölfflin utilizaba un doble proyector durante sus conferencias para mostrar dos diapositivas al mismo tiempo. El sistema, se reproducía en sus libros a partir de un diseño de página donde las imágenes estaban enfrentadas presentando similitudes y contrastes por pares dicotómicos.
Esta oscura pero prolífica relación del trabajo sobre las fiestas florentinas con el viaje a Nuevo México, le permite a Michaud avanzar desde unos primeros artículos sobre Botticelli y Ghirlandaio hacia la elaboración del Atlas Mnemosyne. En otras palabras, el análisis hace posible una conexión entre la problemática de la interpretación de figuras en movimiento y la consideración del movimiento en si mismo como tema y como guía de las investigaciones de Warburg.

En ese camino, los trabajos warburguianos que se ocupan de analizar retratos burgueses de apariencia estática y rigurosa que empiezan a aparecer con gran insistencia en las hagiografías y en los altares durante el Quattrocento dan la clave, para Michaud, sobre una segunda consideración sobre el movimiento. ${ }^{7}$ Dejando atrás la mencionada representación de cuerpos animados por una fuerza exterior, la insistencia del retrato apuntaba a representar personajes animados por una fuerza interior, es decir, seres vivos en actitudes contemplativas. Así, para Warburg, «el arte vivo del retrato" junto con los archivos florentinos sobre los hombres pintados podían despertar a aquellos ricos banqueros y nobles a partir de sus huellas y recuperar sus perdidos «timbres de voz» que el tiempo no podía regresar. Esta reanimación de los personajes, dirá Warburg, "[...] separados de nosotros tanto como de sí mismos", podía acontecer a través del trabajo del historiador, quien volvía a conjugar su cuerpo (la imagen) con su voz (las fuentes textuales). Ante esta declaración casi poética sobre la labor de la historia, Michaud recuerda que asociar imagen y sonido, figura y voz, a partir del movimiento era el deseo que los precursores del cine imaginaban para el futuro de la fotografía. Los experimentos de Edison, primero, y de Dickson, después, se orientaban, en los mismos años, en esa dirección. Sorprende en ese sentido, que tanto Warburg como Edison concibieran la historia del arte y del cine, respectivamente, como una construcción artificial con el fin de reasociar la imagen y el sonido de un sujeto desaparecido no solo para conservar su memoria, sino para reproducirla, para devolverla a la vida.

Con respecto a ello, Michaud también señala la importancia que dio Warburg en el Atlas Mnemosyne a las posibilidades de la reciente reproducción fotográfica, síntoma del gran cambio que había experimentado la historia del arte desde la época de Jacob Burckhardt y que le había proporcionado a la disciplina un novedoso método para manipular imágenes. Este método le permitía a Warburg desplazarse, movilizar la historia del arte a través de sus imágenes, superando con holgura la doble proyección de Heinrich Wölfflin, muy popular en esos años. ${ }^{8}$ Las nuevas opciones fotográficas, por ejemplo, le permitieron a Warburg reconstruir la curva de vida de una mujer del pasado a partir de fotografías de los retratos de María Portinari pintados por Hugo Van Der Goes y, por Hans Memling en diversos momentos de la vida de la dama. De esa manera, el cuadro redispuesto junto a otros según las necesidades del análisis ya no era una escena representada y 
9 Los rituales hopi de los que Warburg escuchó hablar durante el viaje implicaban la participación de serpientes reales que tenían un rol fundamental en el ritual, sobre todo por su injerencia en el pedido por las precipitaciones para las cosechas.

10 Como señala Burucúa (2003), y a pesar de las comparaciones desacertadas que se han hecho entre Warburg y Gustav Jung. las Pathosformeln son supervivencias históricamente determinadas en contextos encadenados y no arquetipos universales. El caso de la serpiente sería para Warburg. casi una excepción, una de las imágenes más esenciales que podía encontrarse tanto en la cultura hopi como en la antigüedad europea y más allá. solitaria sino que «[...] comunicaba lateralmente, por efectos de encadenamiento, con las imágenes que le están inmediatamente yuxtapuestas» (Michaud, 2017, p. 117). Una práctica que en sus últimos años decantaría en un método general de estudio a partir del movimiento entre fotografías.

Este gesto de montaje que el Atlas hace suyo y que es advertido durante el viaje de Warburg produjo, para Michaud, un desplazamiento muy peculiar del orden de los saberes «[...] al tratar de sustituir el estudio de las obras por una actividad más física, Warburg modifica el ejercicio mismo de su disciplina y da a la investigación una significación práctica insólita en la historia del arte» (Michaud, 2017, p. 149). Así, un viaje cambiaba el devenir de una ciencia estática y serena, transformaba la experiencia en documento y, a su vez, hacía del documento una experiencia o una aventura.

La última parte del trabajo de Michaud reseña con detalle las lecturas y los libros que inspiraron el viaje de Warburg, así como la persistencia en su memoria de algunos relatos que recogió y, de algunas ideas que utilizó, casi imperceptiblemente, después. Por ejemplo, Michaud cree advertir el uso de un relato sobre el milagroso sarcófago de un santo que resurge de la tierra en una iglesia de Isleta, en la importancia que le da Warburg, en un estudio sobre los frescos de Ghirlandaio en Santa Trinita, al sentido ascensional y sagrado de la escalera. De la misma manera, la lucha de Apolo y la serpiente Pitón, que se representaba en los intermezzos, parecía acontecer in vivo en el transcurso de los rituales hopi, pero ya no como espectáculo teatral, sino como manipulación real de las fuerzas de la naturaleza a través del contacto con serpientes durante el ritual. ${ }^{9}$ La fascinación warburguiana por las serpientes a partir del viaje, que sugerían más allá de toda iconografía una idea de animación y un "símbolo del ritmo del tiempo", volvía a señalar con claridad su eterno interés por el movimiento (Michaud, 2017, p. 111). La forma serpentina se construía en el pensamiento warburguiano como una «forma patética universal del movimiento» (Michaud, 2017, p. 180). En cierto sentido, la imagen de la serpiente sería la única pathosforma warburguiana que podría adjudicarse ese sentido histórico transversal. ${ }^{10}$

Por su parte, la biblioteca-casa que Warburg edificó en Hamburgo para albergar su vasta colección y para estudiar junto a sus discípulos evocaba, para Michaud, un tipo de circulación entre vivienda y lugar de culto similar al habitáculo sagrado de los hopis, la kiwa. La sala común de lectura en elipse y la biblioteca por la que Warburg se desplazaba en una especie de rito de orientación o de «casualidad bailada» unían su santuario intelectual a una concepción particular del mundo cercana a la de los hopi. No sorprende a esta altura que en el centro de ese recinto se ubicase el Atlas Mnemosyne, para Michaud, un film sin aparato, y que el recinto que lo albergaba, una biblioteca semicircular con butacas, se pareciese a una sala de proyección. 
11 En rigor, el título de la conferencia de Warburg era Imágenes de la región de los indios pueblo en Norteamérica, bautizada por Saxl después El ritual de la serpiente (Freedberg, 2013, p. 117).

\section{Adenda}

En mayo de 1928, un año antes de la muerte de Warburg, su médico, Ludwig Binswanger, le impide regresar a los Estados Unidos ante el sentido deseo del historiador que imploraba por un último viaje de regreso a aquel país para terminar su proyecto:

Mi trabajo toca a su fin. Alrededor de 900 reproducciones están ya dispuestas en las mesas: la cuestión de la presentación, en sustancia, también está resuelta: habría traído el libro terminado de Norteamérica. Habría sido mil veces mejor si me hubiesen dejado partir (Warburg en Michaud, 2017, p. 199).

Algunos años antes, en 1923, la memoria de aquel primer viaje había asaltado a Warburg después de muchos años de silencio respecto al tema, cuando el historiador presentó El ritual de la serpiente (2008) ${ }^{11}$ ante los pacientes del hospital Kreuzlingen, con el objetivo de demostrarles a sus médicos que sus facultades intelectuales estaban intactas. Para ese entonces, dice Michaud, el viaje ya no era solamente un remoto análogo del Renacimiento, sino una metáfora geográfica de su propio pensamiento que estaba por cristalizarse en el Atlas Mnemosyne. Una metáfora muy peligrosa, ya que la conferencia fue enviada a Fritz Saxl con precisas instrucciones de no ser publicada jamás, «una horrible convulsión de rana decapitada que sólo puede ser mostrada a mi querida esposa, a mi hermano Max y al profesor Cassirer" (Freedberg, 2013, p. 14). Con estas palabras Warburg desacreditaba su propio trabajo por carecer, según él, de valor filológico alguno.

Este hoy casi hagiográfico viaje que señala el celebrado y pionero acercamiento warburguiano entre la historia del arte y la antropología no estuvo exento de críticas y, por ejemplo, fue puesto en cuestión por David Freedberg en Las máscaras de Aby Warburg (2013), uno de los pocos estudios críticos sobre el tema. En una lectura en clave poscolonialista, este autor se centra en señalar todo lo que Warburg no había podido ver en la experiencia hopi por su obsesión con el movimiento, la cultura clásica y su latente etnocentrismo. El planteo de Freedberg que pone en cuestión el trabajo de Michaud directamente, por lo menos en dos ocasiones, señala, entre otras cosas, lo forzado y lo vacío de la comparación entre la cultura del Renacimiento y el ritual hopi:

En las danzas hopi no hay movimientos frenéticos, no hay drapeados girantes, no hay cabellos ondeando al viento. Los pasos son deliberados a cada momento, sombríos, profundos y enraizados en la tierra. El viento es una rareza, las caídas de tela volando son inexistentes. Hay incluso menos gemidos en la danza de la serpiente que en las obras. Además, estos nunca son desenfrenados (Freedberg, 2013, p. 63).

Para Freedberg, esta y otras razones hacen del viaje de juventud de Warburg una aproximación muy limitada a la cosmovisión hopi, signada por una grecolatría incapaz de advertir el multiculturalismo 
12 Para profundizar en la relación entre Warburg y Boas ver "Aby Warburg y Franz Boas: un diálogo entre la historia, la teoría del arte y la antropología" (Bovisio, 2009). que convierte al Atlas Mnemosyne en un conjunto de imágenes drenadas, desauratizadasy vueltas ineficaces a partir de la extracción de sus singularidades culturales en pos de construir discutibles comparaciones muchas veces inconducentes (Freedberg, 2013); una afirmación que desacreditaría más de un proyecto en curso para continuar el Atlas. Además, el autor cuestiona la relación de Warburg con Franz Boas, antropólogo considerado el padre del relativismo cultural que guió su viaje y con el que compartió afinidades teóricas comunes que apuntalaban sus prácticas disciplinares. ${ }^{12}$

Sin embargo, pese a que el texto de Freedberg es una lectura muy documentada y de suma importancia para entender un aspecto interesante de la naturaleza profunda de las limitaciones del viaje de Warburg, no anula en gran parte el análisis de Michaud.

Si bien en su viaje Warburg no actuó diferente a cualquier hombre blanco en excursión de su época y sus obsesiones son patentes, las intuiciones que Michaud señala como comparaciones maestras durante el viaje siguen siendo centrales tanto para comprender su interpretación del Renacimiento como para entender la actual vigencia del autor. En este aspecto, el planteo de Michaud se acerca a un problema fundamental del saber no muy considerado actualmente: la importancia que pueden tener la inspiración, la intuición y la experiencia vital en una obra intelectual y espiritual de alto vuelo como es la de Warburg; un aspecto quizás casi imposible de develar completamente, aunque, también, imposible de desatender. Gombrich, más cauto que ninguno, lo sugiere interrogativamente en su biografía: "Quién sabe si toda la carrera de Warburg no estuvo determinada por sus rasgos psicológicos [...]" (2002, p. 281). En estos términos, Michaud se anima a responder la pregunta permaneciendo fiel al sentir de un historiador del arte que vivió una época donde «los pliegues de la vida informaban todo acto de creación intelectual» (Ludueña-Romandini, 2017, p. 13). En ese sentido, la consideración del movimiento como parte fundamental de su obra a partir del discutido viaje entusiasma tanto por su irremediable aproximación interpretativa como por su indiscutible valor ante el desprecio y la negativa de quienes ningunearon la experiencia categóricamente, entre los que se anota, paradójicamente, el propio Warburg. En otros términos, pero atendiendo también a un movimiento, Burucúa se pregunta:

[...] acaso la empresa de Warburg no puede ser entendida como una búsqueda tenaz [...] de las continuidades entre los hombres mágicos y los hombres modernos, a la par que como un rescate del sentido y la vitalidad de la experiencia civilizatoria del Occidente moderno a partir del Renacimiento (Burucúa, 2003, p. 74).

Una afirmación que bien podría caracterizar la finalidad de todos los viajes warburguianos.

Si pensamos con Michaud en Warburg como en ese historiador que miraba trágicamente el retorno del paganismo cuando Mussolini 
firmaba el concordato con el Papa, en 1929, o en aquel paciente extraordinario que habría de demostrar su curación a partir de la elaboración de una conferencia sobre un viaje de juventud, no resulta tan aventurado suponer que detrás de su soberbia escritura académica existía un preocupado pensador de la cultura con una psiquis extraordinariamente sensible a sus vaivenes. Parte de esta condición y su discutida locura le valdrían aquel rechazo académico largamente prolongado y el triunfo de las teorías más pragmáticas y acotadas (aunque igualmente importantes) de sus seguidores directos.

En la misma línea, sería posible también suponer que las experiencias cinematográficas mencionadas, muy lejanas al espectáculo de los Lumiére, habrían fascinado a un hombre como Warburg, a pesar de no tener más que un conocimiento parcial de estos importantes experimentos científicos que se realizaban por aquellos años.

En cualquier caso, el libro de Michaud arriesga sobre una problemática que, a pesar del tiempo, sigue siendo una incógnita en las exégesis warburguianas, al mismo tiempo que despliega la reflexión hacia otros territorios donde la potencia de la analogía se sobrepone a las sutilezas historiográficas. El uso de la iconología para analizar el cine y los mecanismos del cine para comprender el espacio y el desplazamiento de las imágenes en la historia del arte no deja de ser una propuesta prolífica en muchos aspectos. En ese sentido, quizás sea precisamente este tipo de movimiento interdisciplinario, que denota incansable curiosidad y comprometido entusiasmo, una parte fundamental del legado warburguiano. Sobre ello, y pese a sus propias contradicciones, el hoy considerado uno de los grandes intelectuales del siglo XX parece advertirnos sobre el enfriamiento de la siempre necesaria relación entre el mundo intelectual y las producciones culturales. Al mismo tiempo, su complejo semblante señala los riesgos y las virtudes que el apasionamiento intuitivo y los acercamientos disciplinares proponen a la hora de considerar el poder profundo de las imágenes. Una diatriba lanzada a los límites académicos que en la actualidad resulta imposible ignorar.

\section{Referencias}

Bovisio, M. A. (2009). Aby Warburg y Franz Boas: un diálogo entre la historia, la teoría del arte y la antropología. En Actas del $V$ congreso internacional de Teoría e Historia de las Artes: Balances, perspectivas y renovaciones disciplinares de la historia del arte. Buenos Aires, Argentina: CAIA.

Burucúa, J. E. (2003). Historia, arte, cultura. De Aby Warburg a Carlo Ginzburg. Buenos Aires, Argentina: Fondo de Cultura Económica.

Didi-Huberman, G. (2002). La imagen superviviente. Historia del arte y tiempo de fantasmas según Aby Warburg. Madrid, España: Abada.

Didi-Huberman, G. y otros. (2017). Sublevaciones. Buenos Aires, Argentina: Untref. 
Einsestein, S. (1989). Montage and Architecture (ca. 1938). Recuperado de https://cosmopista.files.wordpress.com/2008/10/eisenstein_montageand-architecture.pdf

Freedberg, D. (2013). Las máscaras de Aby Warburg. Buenos Aires, Argentina: Sans soleil.

Gombrich, E. (2002). Aby Warburg. Una biografía intelectual. Madrid, España: Alianza Forma.

Guinzburg, C. (2013). Mitos, emblemas e indicios. Buenos Aires, Argentina: Prometeo.

Freedberg, D. (2013). Las máscaras de Aby Warburg. Buenos Aires, Argentina: Sans soleil.

Ludueña-Romandini, F. (2017). La Ascensión de Atlas. Glosas sobre Aby Warburg. Buenos Aires, Argentina: Miño y Dávila.

Michaud, P. (2017). Aby Warburg y la imagen en movimiento. Buenos Aires, Argentina: Libros UNA.

Warburg, A. (2005). El Renacimiento del paganismo. Aportaciones a la historia cultural del Renacimiento europeo. Madrid, España: Alianza.

Warburg, A. (2008). El ritual de la serpiente. Buenos Aires, Argentina: Sexto Piso.

Warburg, A. (2014). La pervivencia de las imágenes. Buenos Aires, Argentina: Miluno. 